\title{
THE RETENTION OF HABITS BY THE RAT AFTER DESTRUCTION OF THE FRONTAL PORTION OF THE CEREBRUM
}

\author{
S. I. FRANZ AND K, S. LASHLEY
}

From the Government Hospital for the Insane and the Psychological Laboratory of The Johns Hopkins Unversity

Much has been written regarding the neurology of learning and especial attention has been directed to the cerebrum. Comparatively little evidence has been adduced to show what cerebral elements are used in the formation of habits, although recent experimental investigations show that the frontal positions of the cerebrum are utilized by monkeys, dogs, and cats. ${ }^{1}$ In only those animals with a highly developed brain is there a distinct differentiation of the frontal (as an association area) from the central (so-called motor and sensory-kinesthetic) area, and in fact the possibility of the histological differentiation of numerous areas of the brains of many of the lower animals is slight. The relatively simple and homogeneous character of the cerebral cortex in the rodents makes their cerebral physiology worthy of study, and there is the added advantage that the animals acquire habits rapidly and much information is at hand regarding their normal reactions.

At the same time, on account of their low cost and ease of housing, many different experiments on the brain may be made which are not possible with animals having larger and more highly developed brains. Such experiments on rats may be expected to give results of at least suggestive value respecting the functions of corresponding parts of more highly evolved brains. Thus, if it is found that these animals can acquire habits after the removal of certain small or large parts of the cerebrum,

1 For most of the evidence:S. I. Franz, The Frontal Lobes, New York: Science Press, 1907, pp. 64. 
but not after the removal of other parts, or if they can retain but can not acquire habits after certain cerebral destructions, there will exist a basis for further extensive and intensive work on the so-called higher animals. The present work was undertaken with these objects in view.

Several questions were posed, although the facts to answer only a few parts of these questions are now available. Some of the questions are: Do rats retain habits of recent formation after the destruction of certain cerebral regions? Do they retain habits of long standing, or those in which there has been an overtraining or over-learning? Can rats learn after the removal of the whole cortex? If learning and retention are possible after destruction of parts of the cortex, how much and what parts of the brain are necessary for, and what parts are normally used in the formation and the retention of habits? At the present time there are available results of experiments in which the frontal portions of the brain have been destroyed, and in which there have been destructions of two-thirds or more of the whole cortex (that of the cerebral convexity), but only those experiments dealing with the effects of frontal destructions will be reported here.

When the experiments were undertaken there was available a large number of rats which had been trained in a simple maze for other purposes and it was decided to use them in preliminary tests. The maze was built after the pattern of the Yerkes discrimination box (fig 1). It consists of a starting compartment (a) leading by a sliding door to a central alley $(b)$, which at its outer end offers the alternatives of the cul de sac $(c)$ and the alley $(d)$ leading directly to the food (e). A maze of this character had decided advantages for the training of large numbers of animals but is not altogether suitable for tests on retention on account of the speed with which it is learned and the degree of probability that any given correct trial is the result of chance. Incidental observations on the behavior of the animals in the maze are therefore of great importance for the determination of the retention of the habit.

Two activities of the animals in the maze are to be especially 
noted, as their characteristics are evidences of learning or lack of learning, and of retention of the maze habits. These activities relate to the reactions at the door of the starting box and to the shortening of the path to the food. When first introduced into the starting compartment of the maze the rat sniffs at the wire cover, sides, and corners of the compartment and pays no particular attention to the door. When the door is first raised he almost always stands erect and sniffs at its lower edge before venturing into the first alley. With practice his reactions become centered on the door; he tries to push it up or sniffs at the

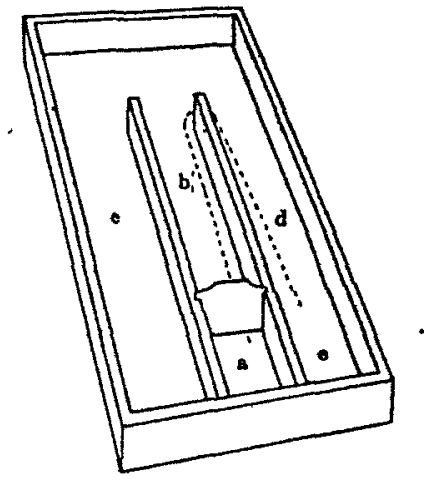

Fig. 1. Stmple Maze

$a$ Starting compartment; $e$, food. The dotted line shows the path taken by well trained animals, keeping close to the right-hand partition and cutting close around the corner.

crack under it. The moment that the experimenter touches the door to open it the rat turns with his head in the right front corner of the starting compartment and as soon as the door is raised high enough to admit his body crawls out into the alley. This behavior is noted in the records of the different animals as "normal orientation to opening door." In his first trials in the maze the rat spends much time in sniffing at the wire cover, the walls, and particularly the corners of the maze. The trained rat can go from the starting compartment to the food in 1.2 seconds. The minimum time on the first trial for any of the sixty rats that have been trained has been eight seconds and 
the modal time is about thirty seconds, most of which is spent in exploratory sniffing. With practice these exploratory movements disappear and the animal runs to the food without a pause. Many animals come to follow the path marked by the dotted line in figure 1 . That is, they keep close to the righthand wall of the middle alley and keep close to the end of the partition in rounding the turn. This cutting down of excess distance and absence of exploratory sniffing are characteristic of the later stages of learning and when they appear in retention tests are therefore conclusive evidence for at least a partial retention of the motor habits of the maze.

In training, ten successive errorless trials were taken as evidence for learning (rarely more than six errors are made in the hundred trials following the achievement of this record). Some of the rats were then given an overtraining of from one to two hundred trials before the destruction of the frontal lobes. Others were operated upon on the day following that on which learning was completed.

The operations were performed under ether anesthesia, and at the end the cut scalp was closed with sutures and was covered with a cotton and collodion dressing.

In some cases a transverse opening about 4 by $8 \mathrm{~mm}$. was made in the skull just back of the fronto-parietal suture and the frontal area of the brain was destroyed by passing a narrow scalpel diagonally forward to the region of the olfactury bulbs and thence cutting out to the sides of the cranial cavity. In other cases two small trephine holes were made in the region of the suture and a spear-pointed needle was inserted through these, pushed through the frontal area and drawn to the sides to cut away the frontal regions. Owing to the small operative field it is not possible to determine the exact extent of the lesion at the time of operation but the possibility of using a large number of animals and of later determination of the extent of the destruction of tissue makes it possible to obtain records of some animals in which the exact lesion desired has been produced.

Most of the animals have been kept for two weeks or more after the operation and in many cases the absorption of the clot 
has progressed to such an extent that it seems advisable to wait until histological examinations of the brains can be made before describing the lesions in detail. Fourteen animals have been operated upon for destruction of the frontal lobes and of these eight have been autopsied. In these the gross lesion has been in every case as extensive as that indicated in figure 2, and in three of the animals has extended back so as to involve the anterior two-thirds of the cortex.

Brief records of the animals studied are given below. Whenever possible, fifteen trials in the maze were obtained from each animal on the day following the operation. The time con-
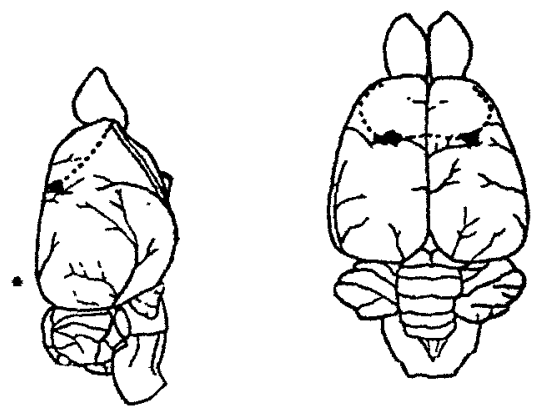

Fig. 2. Diagram of the Extent of the Leston in Rat Hl $q$, as Detremaned by Gross Dissection

sumed in each of these trials in going from the starting compartment to the food dish and the number of errors, either of entering the cul de sac or of turning back upon the true pathway, was recorded. In the following records the total time consumed in these fifteen trials and the total number of errors are compared with the total time and errors of the first fifteen trials made by the same rat in its first training in the maze. The time and number of errors of the rat's first trial in the maze at the beginning of training are also compared with those of the first trial of the retention tests. In addition to this observations are reported on the general behavior of the animals in the maze. 


\section{Animals tested for retention without overtraining}

Experiment 1. G2\%. Ninety-four days old at the beginning of training. Learning was completed in 54 trials at 10 trials per day. No overtraining.

Operation through two trephine holes, followed by extensive hemorrhage. Retention was tested twenty-five hours after the operation. The animal was constantly irritated by inflamation of the nasal sinuses but was otherwise in good condition. Orientation in starting compartment was normal. In every trial except the second the animal kept close to the right-hand wall of the middle alley and cut close to the end of the partition. On the second trial she turned into the entrance of the cul de sac but did not advance more than two inches. Various tests suggest that she was anosmic. A comparison of the records of learning and retention follows.

\begin{tabular}{|c|c|c|c|}
\hline & & LEARNING & RETENTION \\
\hline First 15 trials & $\left\{\begin{array}{l}\text { Total time } \ldots \ldots \ldots \ldots \\
\text { Errors } \ldots \ldots\end{array}\right.$ & $\begin{array}{l}188 \text { seconds } \\
5\end{array}$ & $\begin{array}{l}54 \text { seconds } \\
1(?)\end{array}$ \\
\hline First trial & $\left(\begin{array}{l}\text { Time } \ldots \ldots \ldots \ldots \ldots \ldots \ldots \\
\text { Eirors. } \ldots \ldots \ldots \ldots \ldots\end{array}\right.$ & $\begin{array}{l}15 \text { seconds } \\
0\end{array}$ & $\begin{array}{l}2.6 \text { seconds } \\
0\end{array}$ \\
\hline
\end{tabular}

Experiment 2. G1 9 . Ninety-four days old. Learning was completed in 23 trials with 2 trials per day. No overtraining.

Operation through large transverse opening, followed by considerable hemorrhage but "with recovery of motor coördinntion within half an hour. Retention was tested twenty-six hours after the operation. The rat was very weak, falling over when attempting to make quick turns or to scratch the dressing on her head. She oriented in the starting compartment and gave no evidence of exploratory sniffing in the maze. On the first trial she turned into the cul de sac and wandered back and forth for a few seconds, then went directly to the food. A second error was made on the eleventh trial. The other trials were made correctly but at a rather slow rate. The rat made frequent long stuporous pauses and spent a good bit of time also in scratching at the dressing on her head. On the following day she was given 20 trials in the maze and in every case reached the food without error and in less than four seconds. The records of learning and retention follow. 


\begin{tabular}{|c|c|c|c|}
\hline & & LEARNING & RETENTIOY \\
\hline First 15 trials & $\left\{\begin{array}{l}\text { Total time } \ldots \ldots \ldots \ldots \\
\text { Errors.............. } \ldots .\end{array}\right.$ & $\begin{array}{l}117 \text { seconds } \\
8\end{array}$ & $\begin{array}{l}159 \text { seconds } \\
2\end{array}$ \\
\hline First trial & 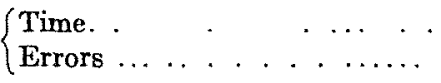 & $\begin{array}{l}10 \text { seconds } \\
1\end{array}$ & $\begin{array}{l}45 \text { seconds } \\
1\end{array}$ \\
\hline
\end{tabular}

Experiment 3. H1\%. Ninety-two days old. Learning was completed in 21 trials with 2 trials per day. No overtraining.

Operation through two trephine holes, with little hemorrhage. Retention was tested twenty-two hours after the operation. The rat oriented in the starting compartment, ran promptly and without exploratory smelling, and never explored the maze in a way comparable to that of normal animals in their first trials. She entered the cul de sac on the first, fifth, eleventh, and thirteenth trials but turned back promptly before reaching the end of it. On the errorless trials she followed the path marked in figure 1. The records of learning and retention were the following.

\begin{tabular}{|c|c|c|c|}
\hline & • & LEARNING & RETENTION \\
\hline First 15 trials & $\left\{\begin{array}{l}\text { Total time } \ldots \ldots \ldots \ldots \ldots \ldots \\
\text { En } \ldots \text { ors. } \ldots \ldots \ldots \ldots \ldots \ldots \ldots \ldots\end{array}\right.$ & $\begin{array}{l}85 \text { seconds } \\
2\end{array}$ & $\begin{array}{l}64 \text { seconds } \\
4\end{array}$ \\
\hline First trial & $\left\{\begin{array}{l}\text { Total time } \ldots \ldots \ldots \ldots \ldots \ldots \ldots \\
\text { Errors } \ldots \ldots \ldots \ldots \ldots \ldots \ldots\end{array}\right.$ & 10 seconds & $\begin{array}{l}8 \text { seconds } \\
1\end{array}$ \\
\hline
\end{tabular}

\section{Animals tested after overtraining}

Experiment 4. G1 ơ". Seventy-three days old. Learning was completed in 21 trials with 10 trials per day. Training was continued for 170 trials.

Destruction of frontal lobes through large transverse opening, followed by little hemorrhage. Retention was tested twenty hours after the operation. The rat oriented correctly in the starting compartment and advanced promptly when the door was opened. On the first trial he turned into the cul de sac and stopped with his head in the first corner, then backed out and went directly to the food. He made a second error on the fourteenth trial. The other trials were correct but were delayed by a peculiar reaction. When he reached the 
first corner after passing the turn he would pause with his nose close in the corner (but without apparent sniffing), then back away and turn down the alley to the food. Tests made by pulling his vibrissae while he was eating indicated that these organs were lacking in tactile sensitivity. The records of learning and retention were the following.

\begin{tabular}{|c|c|c|c|}
\hline & & LEAKNING & RETENTION \\
\hline First 15 trials & 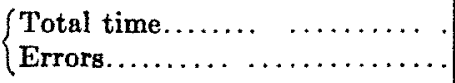 & $\begin{array}{l}1018 \text { seconds } \\
21\end{array}$ & $\begin{array}{l}92 \text { seconds } \\
2\end{array}$ \\
\hline First trial & 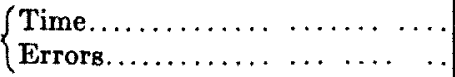 & $\begin{array}{l}34 \text { seconds } \\
1\end{array}$ & $\begin{array}{c}12 \text { seconds } \\
1\end{array}$ \\
\hline
\end{tabular}

Experiment 5. F1 9 . Seventy-five days old. Learning was completed in 90 trials with 10 trials per day. Training was continued for 120 trials.

Operation through a single small trephine hole on the left with little hemorrhage. Retention was tested twenty-six hours later. The rat oriented in the starting compartment, and in the majority of trials followed the path indicated in figure 1 . On the third and fifth trials she retraced a part of the direct pathway to the food and on the tenth trial she swerved so that her head was in the cul do sac but she never ventured entirely off the direct pathway. The records of learning and retention were the following.

\begin{tabular}{|c|c|c|}
\hline & LEARNING & AETENTION \\
\hline First 15 trials $\left\{\begin{array}{l}\text { Total time } \ldots \ldots \ldots \ldots \ldots \ldots \ldots \\
\text { Errors } \ldots \ldots \ldots \ldots \ldots \ldots\end{array}\right.$ & $\begin{array}{l}640 \text { seconds } \\
19\end{array}$ & $\begin{array}{l}44 \text { seconds } \\
2\end{array}$ \\
\hline$\left\{\begin{array}{lllllll}\text { Time. } & \ldots & \ldots & \ldots & \ldots & \ldots & \ldots \\
\text { Errors } \ldots & \ldots & \ldots & \ldots & \ldots & \ldots\end{array}\right.$ & $\begin{array}{l}15 \text { seconds } \\
2\end{array}$ & $\begin{array}{l}4 \text { seconds } \\
0\end{array}$ \\
\hline
\end{tabular}

Experiment 6. F207. Sixty-nine days old. Learning was completed in 24 trials with 2 trials per day. Training was continued for 170 trials.

Operation through large transverse opening with very severe hemorrhage. Retention was tested twenty-three hours after the operation. The rat was active and oriented correctly in the starting compartment. In four trials the rat returned to the starting compartment after ad- 
vancing for his own length into the middle alley, but he did not leave the pathway once in fifteen trials. The records of learning and retention follow.

\begin{tabular}{|c|c|c|}
\hline+ & LEARNINO & RETENTION \\
\hline First 15 trials $\left\{\begin{array}{l}\text { Total time } \ldots \ldots \ldots \\
\text { Errors } \ldots \ldots \ldots\end{array}\right.$ & $\begin{array}{l}93 \text { seconds } \\
7\end{array}$ & $\begin{array}{l}68 \text { seconds } \\
0\end{array}$ \\
\hline$\left\{\begin{array}{l}\text { Time } \ldots \ldots \ldots \ldots \ldots \ldots \\
\text { Errors } \ldots \ldots \ldots \ldots \ldots \ldots\end{array}\right.$ & $\begin{array}{l}13 \text { seconds } \\
1\end{array}$ & $\begin{array}{l}6 \text { seconds } \\
0\end{array}$ \\
\hline
\end{tabular}

Experiment \%. G3 $\sigma^{7}$. Seventy-three days old. Learning was completed in 24 trials with 10 trials per day. Training was continued for 170 trials.

Operation through two trephine holes with little hemorrhage. Retention was tested twenty hours after the operation. He oriented correctly to the opening of the door, ran quickly and followed the path of figure 1 in all but the first and second trials. In the first trial he entered the cul de sac but turned back without exploratory sniffing. In the second trial he put his head into the entrance of the cul de sac, but did not enter it. He appeared to be anosmic. The records of learning and rctention follow.

\begin{tabular}{|c|c|c|c|}
\hline & & LEARNING & RETENTION \\
\hline First 15 trials & $\left\{\begin{array}{l}\text { Total time............. } \\
\text { Errors........... }\end{array}\right.$ & $\begin{array}{l}359 \text { seconds } \\
11\end{array}$ & $\begin{array}{l}55 \text { seconds } \\
1\end{array}$ \\
\hline First trial & $\left\{\begin{array}{l}\text { Time } \ldots \ldots \ldots \ldots \ldots \ldots \\
\text { Errors...... } \ldots \ldots \ldots \ldots \ldots \ldots\end{array}\right.$ & $\begin{array}{l}11 \text { seconds } \\
0\end{array}$ & $\begin{array}{l}8 \text { seconds } \\
1\end{array}$ \\
\hline
\end{tabular}

Experiment 8. F2\%. Seventy-five days old. Learning was completed in 25 trials with 2 trials per day. Training was continued for 200 trials.

Operation by transverse opening with severe hemorrhage. Retention was tested twenty-six hours after the operation. The rat was very weak and her movements were as a rule, slow and hesitating but without marked pauses at the entrance of the cul de sac. On the first trial she explored the cul de sac quickly, but without exploratory sniffing, and had some difficulty in finding the food in the dish. On the 
tenth and thirteenth trials she again entered the cul de sac but did not go to the end. On the other trials she followed the most direct path and cut close around the end of the partition. The records of learning and retention were the following.

\begin{tabular}{|c|c|c|c|}
\hline & & LEARNING & RETENTYON \\
\hline First 15 trials & $\left\{\begin{array}{l}\text { Total time } \ldots \ldots \ldots \\
\text { Errors.............. }\end{array}\right.$ & $\begin{array}{l}203 \text { seconds } \\
7\end{array}$ & $\begin{array}{l}115 \text { seconds } \\
3\end{array}$ \\
\hline First trial & 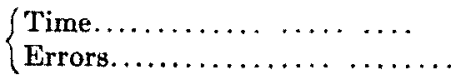 & $\begin{array}{l}60 \text { seconds } \\
1\end{array}$ & $\begin{array}{l}18 \text { seconds } \\
1\end{array}$ \\
\hline
\end{tabular}

Experiment 9. D1 9 . Sixty-nine days old. Learning was completed in 48 trials with 10 trials per day. Training was continued for 200 trials.

The frontal lobes were destroyed by a transverse incision. Retention was tested twenty-four hours after the operation. The rat oriented correctly in the starting compartment, attempting to lift the door by thrusting her nose under it. Two errors were made on the fifth trial. The others were run correctly and by the shortest possible path. There was no exploratory sniffing. The records of learning and retention follow.

\begin{tabular}{|c|c|c|c|}
\hline & & LEARNINO & ' RETENTION \\
\hline First 15 trials & $\left\{\begin{array}{l}\text { Total time........ } \\
\text { Errors } \ldots \ldots \ldots\end{array}\right.$ & $\begin{array}{l}566 \text { seconds } \\
23\end{array}$ & $\begin{array}{l}57 \text { seconds } \\
2\end{array}$ \\
\hline First trial & $\left\{\begin{array}{lllll}\text { Time } \ldots & \ldots & \ldots & \ldots & \ldots\end{array}\right.$ & $\begin{array}{c}18 \text { seconds } \\
1\end{array}$ & $\begin{array}{l}1.8 \text { seconds } \\
0\end{array}$ \\
\hline
\end{tabular}

Experiment 10. B1 $0^{7}$. Sixty-seven days old. Learning was completed in $\mathbf{7 0}$ trials with $\mathbf{1 0}$ trials per day. Training was continued for 200 trials.

The frontal lobes were destroyed by a transverse incision. Retention was tested twenty-eight hours after operation. On the first trial the rat explored the maze hurriedly without pausing to sniff. In the later trials he usually paused and swayed back and forth at the end of the first passage but entered the cul de sac only once, on the 
seventh trial. He oriented in the starting compartment. The records of learning and retention follow.

\begin{tabular}{|c|c|c|c|}
\hline & & LEARNING & RETENTION \\
\hline First 15 trials & $\left\{\begin{array}{l}\text { Total time.. } \ldots \ldots \ldots \ldots \ldots \ldots \\
\text { Errors } \ldots \ldots \ldots \ldots \ldots \ldots \ldots\end{array}\right.$ & $\begin{array}{l}1797 \text { seconds } \\
33\end{array}$ & $\begin{array}{l}137 \text { seconds } \\
2\end{array}$ \\
\hline First trial & 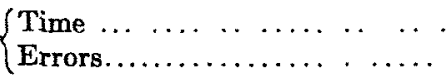 & $\begin{array}{l}32 \text { seconds } \\
1\end{array}$ & $\begin{array}{c}12 \text { seconds } \\
1\end{array}$ \\
\hline
\end{tabular}

Experiment 11. F30?. Sixty-nine days old. Learning was completed in 60 trials with ten trials per day. Training was continued for 200 trials.

The anterior third of the cortex was destroyed. Little hemorrhage. Retention was tested twenty-two hours after the operation. On the first trial the rat turned into the cul de sac and ran half way to the end, then turned back and went directly to the food. He made no other error in the fifteen trials of the test, and followed the most direct route to the food. His records for learning and retention follow.

\begin{tabular}{|c|c|c|}
\hline - & LFARAIINO & RETENTION \\
\hline 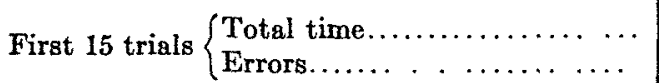 & $\begin{array}{l}428 \text { seconds } \\
1 \mathrm{~J}\end{array}$ & $\begin{array}{c}50 \text { seconds } \\
1\end{array}$ \\
\hline First trial $\quad\left\{\begin{array}{l}\text { Total time } \ldots \ldots \ldots \ldots \ldots \ldots \\
\text { Errors } \ldots \ldots \ldots \ldots\end{array}\right.$ & $\begin{array}{l}175 \text { seconds } \\
4\end{array}$ & $\begin{array}{c}11 \text { seconds } \\
1\end{array}$ \\
\hline
\end{tabular}

Experiment 12. G40 $\sigma^{7}$. Seventy-three days old. Learning was completed in 16 trials with 2 trials per day. Training was continued for 200 trials.

Frontal lobes were removed by a transverse incision in the region of the fronto-parietal suture. Retention was tested twenty hours after the operation. The animal was very weak and spastic. He reacted promptly to the maze, however, orienting in the starting compartment and never hesitating at the turn in the maze. He had some little difficulty in finding the food, pushing under instead of above the edge of the dish. After 10 trials he began to show evidence of fatigue so the remaining trials for retention were postponed for two days when he had regained almost normal strength. The records of learning and retention follow. 


\begin{tabular}{|c|c|c|c|}
\hline & & LEA RNING & RETENTION \\
\hline First 15 trials & $\left\{\begin{array}{l}\text { Total time } \ldots \ldots \ldots \ldots \ldots \\
\text { Errors } \ldots \ldots \ldots \ldots \ldots \ldots\end{array}\right.$ & $\begin{array}{l}135 \text { seconds } \\
2\end{array}$ & $\begin{array}{l}51 \text { seconds } \\
0\end{array}$ \\
\hline First trial & $\left\{\begin{array}{llllll}\text { Time. } & \ldots & \ldots & \ldots & \cdots \\
\text { Errors. } & \ldots & \ldots & \ldots & \ldots\end{array}\right.$ & $\begin{array}{l}20 \text { seconds } \\
1\end{array}$ & $\begin{array}{l}2 \text { seconds } \\
0\end{array}$ \\
\hline
\end{tabular}

Experiment 18. G20'. Sixty-nine days old. Learning was eompleted in 24 trials with 2 trials per day. Training was continued for 200 trials.

Frontal lobes destroyed by a transverse incision. Retention was tested twenty-two hours after the operation. The animal was very weak and spastic. He had great difficulty in finding the food and gnawed at the edge of the dish as much as at the bread. Nevertheless he followed the direct path to the food with never a suggestion of reaction to the entrance to the cul de sac. During the trials there were many stuporous pauses (one of fifty seconds duration, which accounts for the long time consumed in the fifteen trials recorded below) so, after five trials the rat was returned to the home cage and the tests continued two days later when he had recovered strength. The records of learning and retention follow.

\begin{tabular}{|c|c|c|}
\hline & LEARNING & RETENTION \\
\hline 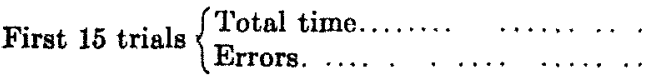 & $\begin{array}{l}134 \text { seconds } \\
3\end{array}$ & $\begin{array}{l}123 \text { seconds } \\
0\end{array}$ \\
\hline 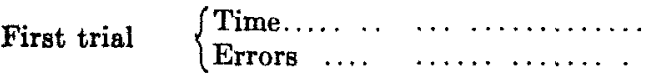 & $\begin{array}{c}21 \text { seconds } \\
1\end{array}$ & $\begin{array}{l}8 \text { seconds } \\
0\end{array}$ \\
\hline
\end{tabular}

Experiment 14. F4o $\sigma^{x}$. Sixty-nine days old. Learning was completed in 18 trials with 2 trials per day. Training was continued for 120 trials.

Frontal lobes destroyed by a transverse incision through a small trephine hole on the left. Retention tested 20 hours after operation. The animal had developed a left hemi-paresis and failed to leave the starting compartment of the maze in an hour on each of three consecutive days. Autopsy showed an extensive clot over the orbital surface of the right hemisphere, extending back to the pons. 


\section{SUMMARY OF RESULTS OF EXPERIMENTS}

The records of time and errors have been summarized in table 1. From the averages it appears that the rats which were not overtrained required 29 per cent less time for the first 15 trials after the destruction of the frontal lobes and made 53 per cent

TABLE 1

The time required for reaching the food and the number of errors made by rats in learning the maze and in the retention tests aftar the destruction of the frontal lobes

Animals without overtraining

\begin{tabular}{|c|c|c|c|c|c|c|}
\hline \multirow{3}{*}{ NUMEER } & \multicolumn{3}{|c|}{ Training } & \multicolumn{3}{|c|}{ RETENTION } \\
\hline & \multicolumn{2}{|c|}{ First 15 trials } & \multirow{2}{*}{ First trual } & \multicolumn{2}{|c|}{ Furst 15 trials } & \multirow{2}{*}{ First trial } \\
\hline & Time & Errors & & Timo & Errots & \\
\hline $\begin{array}{l}\mathrm{G} 29 \ldots \ldots \ldots \ldots \\
\mathrm{G} 19 \ldots \ldots \ldots \ldots \\
\mathrm{H} 19 \ldots \ldots \ldots \ldots\end{array}$ & $\begin{array}{r}188 \\
117 \\
85\end{array}$ & $\begin{array}{l}5 \\
8 \\
2\end{array}$ & $\begin{array}{l}15 \\
10 \\
10\end{array}$ & $\begin{array}{r}54 \\
159 \\
64\end{array}$ & $\begin{array}{l}1(?) \\
2 \\
4\end{array}$ & $\begin{array}{l}2.6 \\
45 \\
8\end{array}$ \\
\hline & 390 & 15 & 35 & 277 & 7 & 556 \\
\hline \multicolumn{7}{|c|}{ Animals overtrained } \\
\hline 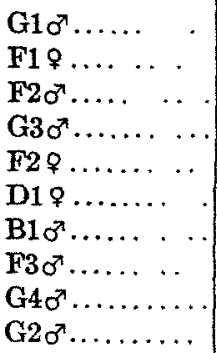 & $\begin{array}{r}1018 \\
640 \\
93 \\
359 \\
203 \\
566 \\
1797 \\
428 \\
135 \\
134\end{array}$ & $\begin{array}{r}21 \\
19 \\
7 \\
11 \\
7 \\
23 \\
33 \\
11 \\
2 \\
3\end{array}$ & $\begin{array}{r}34 \\
15 \\
13 \\
11 \\
60 \\
18 \\
32 \\
175 \\
20 \\
31\end{array}$ & $\begin{array}{r}92 \\
44 \\
68 \\
55 \\
115 \\
57 \\
137 \\
50 \\
51 \\
123\end{array}$ & $\begin{array}{l}2 \\
2 \\
0 \\
1 \\
3 \\
2 \\
2 \\
1 \\
0 \\
0\end{array}$ & $\begin{array}{c}12 \\
4 \\
6 \\
8 \\
18 \\
1.8 \\
12 \\
11 \\
2 \\
8\end{array}$ \\
\hline & 5408 & 137 & 399 & 791 & 13 & 82.8 \\
\hline
\end{tabular}

fewer errors than they did in learning the maze. This in itself is evidence for a partial retention of the habit. When considered in connection with the data on their behavior in the maze it shows that there was little if any loss that can not be accounted for by the distracting effects of the head bandages and the general shock effects of the operation. . None of the animals showed 
the exploratory sniffing at cracks and corners which is so characteristic of the untrained rat in the maze. All were tested immediately after the retention tests by being placed in a strange cage with food and all spent at least thirty seconds in exploring the cage before pausing at the food, so that the lack of exploratory activities in the maze must be looked upon as due to retention of the habit and not to a general sluggishness resulting from the operations. The three rats which were not overtrained oriented in the starting compartment and two regularly followed the path marked in figure 1 . The abnormality of behavior of the third (G1 q) was probably due to loss of sensitivity of the vibrissae.

The animals which were overtrained required 87 per cent less time for the first fifteen trials after operation and made 90 per cent fewer errors than in their initial learning. This, in addition to the data on individual behavior in the maze shows that there was practically no loss of the habit resulting from the destruction of the frontal lobes.

There is an apparent difference in the amount of retention between animals which were over-trained and those which were trained only until they had learned the problem. This difference is probably not so great as is indicated by the averages because the long time spent by the non-overtrained group is the result of the inclusion of the rat G1 \& which spent a great deal of time in trying to remove the dressing from its head.

Only one animal did not show evidence of the maze habit after removal of the frontal portions of the brain. This animal showed such an amount of muscular weakness, or apathy, that the running of the maze was not attempted by it even after the fashion of an untrained animal. With this exception the tests gave indisputable evidence of the retention of the habit after the frontal portions of both hemispheres has been excised. Moreover, the evidence is more compelling because of some obvious behavior disturbances in a number of the animals. Thus, it has been reported of the second animal, G1 o that, although the time for running the maze after the operation was greater than in the training series its other behavior relating directly to the 
maze was retained. The time variation (lengthening) was due entirely to changes in its physical condition other than those necessarily related to its maze activities. That this is so will be realized when it is remembered that the delays were made up of periods of scratching its head-dressing and of long stuporous or apathetic pauses. In the fourth animal the sensibility of the vibrissae was decreased, perhaps they were anesthetic, and the short times for running the maze after the operation are especially noteworthy. The twelfth and thirteenth animals were weak and spastic, and exhibited abnormal reactions in connection with the food dish, but both managed to find the correct path quite promptly. The time for the first fifteen trials of the thirteenth animal, G2 $0^{7}$, after operation was only slightly less than that of the corresponding period of training, but the long stuporous pauses account for much of the time that was taken.

As a whole, therefore, the experiments show that in the white rat the removal of large parts of the frontal portions of the brain does not greatly interfere with a learned reaction. This is the more remarkable since it seems probable that the so-called motor area is in that region and that in most, if not, all, of the cases there was a destruction or abolition of the motor connections. While it can not be concluded with certainty, it seems likely that the motor derangements which were exhibited by many of the rats were due to the interference with the normal efferent impulses and not to the general anemia (from the hemorrhage of the operation). Some of the animals also showed obvious disturbances of sensibility, the observations indicating that in some the stimuli to the vibrissae and olfactory stimuli did not give normal effects. In view of the importance of these two forms of sensibility in the rat's reactions, we are led to wonder whether these retain their predominance in the animal's learned activities, or are replaced by other forms of sensibility, such as the general kinesthetic. Although the results give plain evidence of non-interference (relative, to be sure) with learned reactions when the frontal portions of the brain have been destroyed they also suggest that the habit reaction is not neces- 
sarily cortical in these animals. Other experiments which have been performed bear out this conclusion, but it seems best to reserve the account of these other tests until careful cerebral examipations have been completed. 